\title{
Optimality of AIC in inference about Brownian motion
}

\author{
Arijit Chakrabarti · Jayanta K. Ghosh
}

Published online: 15 November 2006

(C) The Institute of Statistical Mathematics, Tokyo 2006

\section{Erratum to: AISM 58: 1-20 DOI 10.1007/s10463-005-0007-7}

The original version of the history unfortunately contained a mistake. The correct approval history is given here.

Received: 12 February 2004 / Revised: 10 December 2004

The online version of the original article can be found at http://dx.doi.org/10.1007/s10463-005-0007-7.

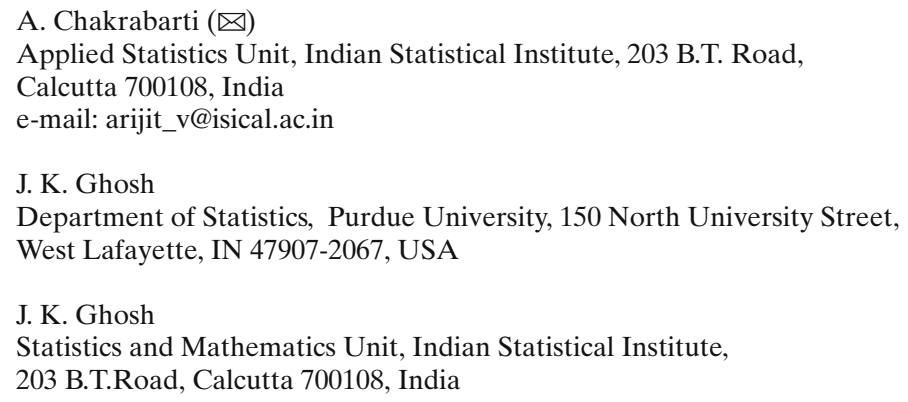

